\title{
A EMERGÊNCIA DE SIGNIFICADOS SOBRE O CONCEITO DE ETNOMODELAGEM DURANTE UMA AÇÃO FORMATIVA DE PROFESSORES DE MATEMÁTICA
}

\section{The Emergency of Meanings About the Concept of Ethnomodelling During a Training Action for Mathematics Teachers}

\author{
José Lucas Matias de Eça ${ }^{1}$ \\ Jurema Lindote Botelho Peixoto ${ }^{2}$ \\ Zulma Elizabete de Freitas Madruga ${ }^{3}$
}

Resumo: A Etnomodelagem está se consolidando como constructo teórico-metodológico e político na área de Educação Matemática, quando permite a exploração de saberes matematizantes praticados em diferentes grupos sociais (Etnomatemática), normalmente minoritários, em caráter formal - traduzidos por meio de técnicas (Modelagem). As ações pedagógicas fundamentadas nessa abordagem podem permitir a construção de cenários educativos mais críticos envolvendo professores e estudantes. Para que isso se realize, os professores precisam conhecer e refletir sobre esse conceito. O objetivo deste estudo foi investigar os significados da Etnomodelagem que emergiram durante uma ação formativa com professores de Matemática de um município do interior da Bahia. Foi realizada uma ação formativa, em seis encontros, com todos os professores que lecionavam matemática nos anos finais do Ensino Fundamental no município, sendo que o corpus deste artigo é composto de apenas três professores que aceitaram responder a uma entrevista semiestruturada abordando aspectos da formação. Para análise dos dados, foi utilizada a Análise Textual Discursiva (ATD). Desta análise emergiram quatro categorias: processo formativo, docência, currículo e abordagem dialógica, sendo esta última analisada neste artigo. Os resultados apontaram que os professores participantes do processo formativo compreenderam a Etnomodelagem como uma abordagem metodológica que visa principalmente à valorização dos saberes matemáticos locais dos estudantes e da Matemática praticada pelos diversos grupos culturais e sociais aos quais pertencem.

Palavras-chave: Educação Matemática. Etnomodelagem. Formação de professores.

\footnotetext{
Abstract: Ethnomodelling is consolidating itself as a theoretical-methodological and political construct in the area of Mathematics Education, when it allows the exploration of mathematical

${ }^{1}$ Mestre em Educação em Ciências e Matemática, Universidade Estadual de Santa Cruz (UESC), campus Ilhéus. Professor da rede municipal de ensino, Cairu, Bahia, Brasil. ORCID iD: https://orcid.org/0000-0001-5848-2100. E-mail: lucasceeft@hotmail.com.

2 Doutora em Difusão do Conhecimento, Universidade Federal da Bahia (UFBA), campus Salvador. Professora adjunta da Universidade Estadual de Santa Cruz (UESC), Ilhéus, Bahia, Brasil. ORCID iD: https://orcid.org/00000002-5648-7001. E-mail: peixotojurema@ gmail.com.

3 Doutora em Educação em Ciências e Matemática (PUCRS), campus Rio Grande do Sul. Professora da Universidade Federal do Recôncavo da Bahia (UFRB), Amargosa, Bahia, Brasil. ORCID iD: http://orcid.org/0000-0003-1674-0479. E-mail: betemadruga@ufrb.edu.br.
} 
knowledge practiced in different social groups (Ethnomathematics), normally minorities, in a formal character - translated through techniques (Modelling). Pedagogical actions based on this approach can allow the construction of more critical educational scenarios involving teachers and students. For this to happen, teachers need to know and reflect on this concept. The aim of this study was to investigate the meanings of Ethnomodelling that emerged during a formative action with Mathematics teachers from a municipality in the interior of Bahia. A training action was carried out, in six meetings, with all teachers who taught mathematics in the final years of elementary school, in the city, and the corpus of this article is composed of only three teachers who accepted to respond to a semi-structured interview addressing aspects of training. For data analysis, Discursive Textual Analysis (ATD) was used. From this analysis, four categories emerged: formative process; teaching; curriculum, and dialogic approach, the latter being analyzed in this article. The results showed that the teachers participating in the training process understood Ethnomodelling as a methodological approach that mainly aims at valuing the local mathematical knowledge of students, and the Mathematics practiced by the various cultural and social groups to which they belong.

Keywords: Mathematics Education. Ethnomodelling. Teacher training.

\section{Introdução}

As experiências docentes vivenciadas no âmbito da Educação Básica e do Ensino Superior que omitem as relações culturais envolvidas na construção dos conceitos, identificando práticas apartadas da realidade sociocultural do estudante, instigaram a busca por vertentes teóricas que subsidiam um ensino de Matemática mais humanizado. Muitas vezes, as lentes do tradicionalismo no ensino têm condicionado a percepção do conhecimento matemático como algo pronto e acabado, refutando a compreensão da Matemática como um produto do meio social e, portanto, um processo humano.

As tendências que compõem o acervo conceitual da Educação Matemática estão formando o pilar teórico para que as pesquisas desenvolvidas em sua prática docente tenham outro contorno: uma conexão com a realidade dos sujeitos envolvidos - professor e estudante. A consequência disso é o enaltecimento da pluralidade de saberes locais que diferentes sujeitos produzem em seus territórios, principalmente aqueles vinculados ao conhecimento matemático. Aliado a esse contexto, há uma efervescência constante nas discussões sobre a formação de professores, uma vez que as diretrizes pedagógicas mudaram de sentido após as homologações da Base Nacional Comum Curricular - BNCC (BRASIL, 2017) e do Documento Curricular Referencial da Bahia - DCRB (BAHIA, 2019).

A busca por metodologias e aportes teóricos que coadunam com uma prática pedagógica pautada na construção de conhecimento, por meio do desenvolvimento de habilidades e competências, se fortalecem ainda mais quando se associam com os fenômenos presentes nas diferentes realidades dos estudantes. Nesse sentido, embora não seja, ainda, uma das tendências que se apresentam como alternativa para os processos de ensino e de aprendizagem da Matemática no campo da Educação Matemática, considera-se a Etnomodelagem, proposta por Rosa e Orey (2017), como um constructo teórico-metodológico que permite unir as técnicas formais da Matemática, por meio da Modelagem, com a valorização dos saberes locais que diferentes grupos sociais praticam em suas atividades diárias - Etnomatemática.

Além disso, segundo Eça e Madruga (2021), a Etnomodelagem constitui um instrumento político-pedagógico que pode conduzir os estudantes à reflexão sobre os "[...] 
caminhos históricos que os constituem como membros de grupos sociais minoritários. O engajamento a essas discussões pode deflagrar no estudante símbolos de resistência contra o sistema, que normalmente é opressor sobre eles" (EÇA; MADRUGA, 2021, p. 21). Sob esses aspectos, a Etnomodelagem está se consolidando como uma proposta metodológica para o ensino de Matemática, pois visa explorar os saberes matematizantes praticados em diferentes grupos sociais (Etnomatemática), normalmente minoritários, em caráter formal - traduzidos por meio de técnicas (Modelagem) - ou não formal, para dentro dos ambientes escolares para fins político-pedagógicos: ações necessárias, mas que por muito tempo foram negligenciadas pelos interesses hegemônicos (ROSA; OREY, 2017).

Aliado ao exposto, a utilização da Etnomodelagem na prática docente busca integrar mutuamente os saberes institucionalizados pela academia com os saberes constituídos e praticados por membros de diferentes contextos socioculturais, por meio da dialogicidade, descaracterizando, assim, a supremacia de um saber sobre o outro. Essa perspectiva teórica se opõe à cosmovisão eurocentralizada que tem perdurado e se ramificado nas instituições, negligenciando outros saberes que nascem em berços marginalizados. Em vista disso, fundamentar as ações pedagógicas por meio da Etnomodelagem é construir cenários educativos que visam à formação crítica de professores e estudantes sob uma perspectiva sociocultural.

Para tanto, faz-se necessário compartilhar e refletir com professores abordagens teóricas no campo da Educação Matemática que considerem essa perspectiva no desenvolvimento das aulas. Dessa forma, o objetivo deste estudo foi investigar os significados da Etnomodelagem que emergiram durante uma ação formativa com professores de Matemática de um município do interior da Bahia, buscando-se responder a seguinte questão de pesquisa: Quais os significados da Etnomodelagem que emergiram durante uma ação formativa com professores de Matemática de um município do interior da Bahia?

Assim, na próxima seção será abordado o conceito de Etnomodelagem, realizando-se em seguida a apresentação dos procedimentos metodológicos que descrevem os participantes do estudo, os instrumentos de produção e análise de dados, bem como as considerações finais.

\section{Etnomodelagem}

A Etnomodelagem, fruto da intercepção entre a Etnomatemática, a Modelagem Matemática (MM) e a Antropologia Cultural (ROSA; OREY, 2017), apresenta-se como uma abordagem metodológica alternativa ao ensino de Matemática, que possui em base epistêmica conceitos que visam descortinar saberes de diferentes grupos socioculturais que outrora foram ocultados, oprimidos e renegados pelas classes hegemônicas.

A Etnomodelagem abre "[...] um leque de oportunidades para se construir saberes matemáticos pautados nos fazeres culturais que estão à luz, porém ocultos para os olhares rígidos, carregados de preconceitos" (EÇA; MADRUGA, 2021, p. 16), retroalimentados por vestígios de uma cosmovisão eurocêntrica que ainda se mantém nas estruturas sociais da atualidade. Nesse sentido, salienta-se que

\footnotetext{
As abordagens da Etnomodelagem se fecundam a partir da construção do saber matemático do/no seio cultural das classes oprimidas, servindo de ferramenta sociopolítica para os membros desses grupos que são invisibilizados pela sociedade, que por sua vez foi historicamente doutrinada a reconhecer e valorizar, quase que unicamente, os saberes oriundos da Europa: os saberes hegemônicos, afogando, dessa forma, toda e qualquer caravela pensante que navegue em outros mares (EÇA; MADRUGA, 2021, p. 16).
} 
Observa-se, diante desta afirmação, que a Etnomodelagem, subsidiada pela fusão entre a Etnomatemática e a MM, demarca em sua ação pedagógica uma bandeira em prol da aproximação entre os saberes matemáticos globais (sistematizados pelo prisma acadêmico/ escolar e realizado pelos outsiders ${ }^{4}$ ) e locais (constituídos na prática cotidiana pelos insiders ${ }^{5}$ ), de modo a não haver diferenciação de níveis de conhecimentos; apenas a percepção de que existem maneiras diferentes de abordar os conceitos matemáticos (ROSA; OREY, 2017).

Para tanto, utilizam-se das abordagens êmica e ética para nortear suas ações políticopedagógicas que representam "[...] uma analogia entre os observadores de dentro (insiders, êmicos, locais) e os observadores de fora (outsiders, éticos, globais)" (RODRIGUES; OREY; ROSA, 2021, p. 63). Isto é, prega-se no desenvolvimento da abordagem êmica a compressão das atividades matematizantes praticadas pelos membros de um grupo social nos diferentes fenômenos que compõem seu contexto sociocultural. Já a abordagem ética investiga a relação entre essas práticas com os conceitos formais da Matemática sob o olhar dos observadores externos e sua respectiva transmutação do conhecimento local para o acadêmico (ROSA; OREY, 2017). Segundo Gonçalves (2021, p. 4-5), "essas abordagens podem subsidiar o pesquisador na adoção de um olhar cuidadoso sobre o contexto investigado que, ao invés de sobrepor sua visão de mundo sobre os elementos observados, valoriza e reconhece as diferentes perspectivas, estabelecendo um diálogo entre elas".

As abordagens êmicas e éticas, segundo Rosa e Orey (2017), são indissociáveis e indicotomizáveis. Utilizá-las de modo confluente, harmônico e integrado é gerar uma terceira abordagem chamada de dialógica. Essa abordagem, fruto do diálogo simétrico, mantido com alteridade, promove uma intersecção entre diferentes modos de pensamentos teóricos e empíricos sobre determinado tema, respeitando-as mutuamente, sem haver, porém, justaposição de um saber em relação ao outro; ao contrário, são entendidos em um mesmo horizonte planificado. Faz-se necessário, portanto, “[...] cultivar um respeito mútuo entre os diferentes saberes, por meio de uma mediação dialógica, para, assim, não haver supremacia de um saber sobre o outro, o que leva, consequentemente, à prática de se distanciar das raízes que alimentam as injustiças sociais" (EÇA; PEIXOTO; MADRUGA, 2021, p. 9-10).

O emprego desse conceito na ação pedagógica "prevê a promoção e desenvolvimento da justiça, cidadania, equidade e demarca um território de enfrentamento a qualquer forma de soberania intelectual de um povo sobre outro" (EÇA; MADRUGA, 2021, p. 17). Fato que envolve o conceito da transculturalidade, pois a "[...] globalização se aplica à combinação dessas duas abordagens que captam a proporcionalidade do local em relação ao global e viceversa" (ROSA; OREY, 2020, p. 277). Dessa forma,

[...] essa relação dialógica se constitui em um aspecto relevante da Etnomodelagem, pois é uma das maneiras pelas quais as culturas glocalizam as suas ideias, os seus procedimentos e as suas práticas. Por conseguinte, quando culturas se encontram e se envolvem através de interações e diálogos, as ideias, os procedimentos e as práticas matemáticas locais e universais emergem desses contextos. Portanto, o reconhecimento das semelhanças dessas práticas é importante para possibilitar a percepção de que o conhecimento local pode possuir elementos globais e vice-versa (ROSA; OREY, 2020, p. 278).

Essa dialogicidade entre os envolvidos - insiders e outsiders - que os autores apontam nessa afirmação pode resultar em conceitos matemáticos, que por sua vez podem ser traduzidos por meio de técnicas inerentes a esse campo do conhecimento. Esse processo de "garimpagem

\footnotetext{
${ }^{4}$ Membros externos ao grupo social investigado: pesquisador(a), professor(a), estudante.

${ }^{5}$ Membros internos do grupo social investigado.
} 
dos saberes extraescolares, via as abordagens que fundamentam a Etnomodelagem, descortina não apenas a tradução de saberes para a linguagem matemática, mas desvela saberes ofuscados" pelo prisma das lentes colonizadoras que, aliadas a uma visão eurocentralizada, ainda permeiam a sociedade atual (EÇA; MADRUGA, 2021, p. 19).

Essa compreensão pode deflagrar na construção de uma representação matemática que sintetiza os fenômenos constituídos nas práticas socioculturais dos membros dos grupos sociais chamados de etnomodelos, que, sinteticamente, significam '[...] artefatos culturais utilizados para possibilitar o entendimento e a compreensão de sistemas retirados da realidade dos membros de culturas distintas" (RODRIGUES; OREY; ROSA, 2021, p. 64). Segundo Rosa e Orey $(2014$, p. 143),

[...] no processo de tradução de sistemas desenvolvidos localmente para a Matemática escolar, a elaboração de etnomodelos ocorre a partir das ferramentas culturalmente mediadas que funcionam como uma ponte para explicar academicamente essas práticas para aprimorar as resoluções impostas do dia a dia ligados a fatores naturais e sociais.

Assim, de acordo com a perspectiva dos autores, os indivíduos elaboram etnomodelos - que podem ser êmicos, éticos ou dialógicos, a depender de quem o produz - para sistematizar a produção matemática resultante das situações-problemas que lhes são exigidas diariamente. A Figura 1 representa uma síntese da constituição das abordagens local, global e glocal, bem como dos etnomodelos êmicos, éticos ou dialógicos no desenvolvimento da Etnomodelagem.

Figura 1 - Abordagens e etnomodelos da Etnomodelagem.

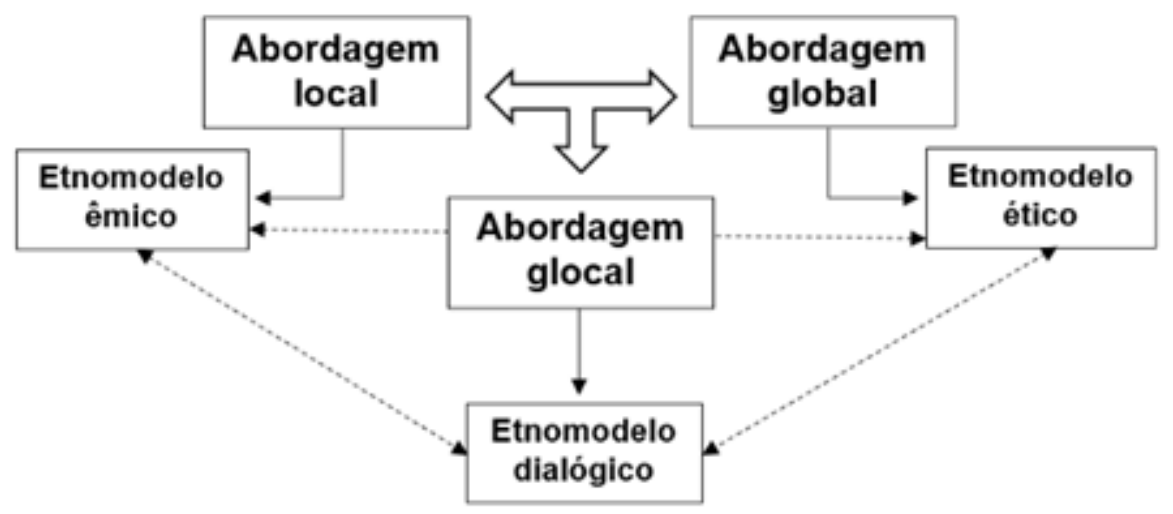

Fonte: Gonçalves (2021, p. 5).

Nessa direção, a Etnomodelagem tem como princípio fundante, também, a facilitação e transmissão dos saberes de geração para geração, de um determinado grupo social, mantendo viva, assim, sua cultura ao longo do tempo. Nesse sentido, Rosa e Orey (2014, p. 134) afirmam que:

Com a tradução de práticas matemáticas locais, os membros de grupos culturais distintos podem incorporar a transculturalidade, pois quando os espaços social e físico facilitam a expansão do conhecimento desenvolvido pelos seus membros, os regionalismos e o determinismo da herança sociocultural são rompidos, pois ultrapassam as fronteiras culturais.

Sob esse entendimento, a ação pedagógica que se baseia nos princípios da transculturalidade está interligada à pretensão de integração de saberes sob uma perspectiva 
horizontal de classes, povos, culturas e práticas, refutando, assim, o ponto de vista homogeneizador que visa reproduzir uma concepção aliada às "facetas que encobrem, ofuscam e deslegitimam os saberes matemáticos produzidos por representantes dos grupos sociais/culturais em diferentes espaços não formais, constituídos por diversos setores que compõem a sociedade" (EÇA; PEIXOTO; MADRUGA, 2021, p. 21).

Para além dos processos de ensino e de aprendizagem da Matemática, a Etnomodelagem ganha contornos políticos-pedagógicos nítidos quanto a sua percepção teórico-prática: a produção de saberes matemáticos deve dialogar com o compromisso social no desenvolvimento da cidadania, autonomia, emancipação social, empoderamento de classe no ambiente escolar, tornando-se, assim, uma bandeira de luta contra a visão hegemônica que prolifera desigualdades/exclusões sociais. $\mathrm{O}$ que, sobremaneira, requer uma mudança no currículo, que privilegia os objetos de conhecimento como única via de construção do conhecimento.

Para isso, é necessário superar essa visão, valorizando, sobremodo, as práticas matematizantes que são realizadas em diferentes contextos sociais. Nesse viés, a Etnomodelagem se candidata a atingir essa finalidade, principalmente por englobar temáticas que envolvem a diversidade cultural e contextos repletos de saberes matemáticos, os quais podem ser visibilizados no âmbito escolar. Em convergência a isso, Eça, Peixoto e Madruga (2021, p. 6) afirmam que "[...] a escola deve (re)estruturar seu currículo, de modo a considerar os saberes que são produzidos em setores da sociedade e estão marginalizados e ocultos sob seu olhar; caso contrário, [...] torna-se um espaço de cumplicidade com essas exclusões/injustiças sociais".

\section{Aspectos metodológicos}

Este artigo é recorte de uma pesquisa, na qual foi realizada uma proposta formativa com um viés colaborativo, constituída em ações teóricas/práticas sob as fundamentações da MM, da Etnomatemática e da Etnomodelagem que se aproximavam da realidade dos professores participantes, inseridos na Educação do Campo. A intencionalidade dessas ações foi que houvesse uma dinâmica em grupo de tal forma que todos possuíssem espaço para construir e desconstruir paradigmas sobre o ensino de Matemática, em especial aqueles que envolviam as práticas dos professores participantes.

Para efetivar as ações formativas com os professores que lecionavam matemática em 2019 em um município do interior da Bahia, foi construída uma proposta e apresentada à Secretaria Municipal de Educação (Seduc) deste município, a fim de avaliar se tal intenção estava alinhada aos seus interesses. Antes do aceite, os técnicos da Seduc solicitaram que fossem tratadas no ciclo formativo questões que atendessem às prerrogativas da BNCC e do Documento Curricular Referencial da Bahia (DCRB), especialmente vinculando-as à construção de saberes, tendo como base os saberes locais.

O intuito, após a homologação da proposta, era o de visitar as escolas, apresentá-la e dialogar sobre a mesma pessoalmente. Porém, por falta de compatibilidade de horários com o transporte para a ida às Escolas no Campo, essa ideia foi substituída pelo envio de e-mails aos professores. No entanto, quando utilizamos outra rede multimídia, o WhatsApp, o engajamento e retorno ganhou um contorno mais nítido. Assim, foi criado um grupo no próprio WhatsApp para facilitar a comunicação. Por meio deste veículo de mensagens, mantivemos contato e diluímos todos os objetivos da ação formativa. Como resultado, todos os professores contatados aceitaram participar voluntariamente da formação. 
A ação formativa, realizada em 2019, envolveu seis momentos, isto é, seis turnos, distribuídos em três dias distintos. Nesses momentos, o diálogo abordou os aportes teóricos da Etnomatemática, MM e o constructo da Etnomodelagem, buscando relacionar as possibilidades e limites dessas abordagens com o contexto social dos professores e estudantes. Segue o planejamento das ações realizadas na formação de modo pormenorizado, por meio do Quadro 1 .

Quadro 1 - Cronograma dos encontros formativos com o grupo de professores.

\begin{tabular}{|c|c|c|c|}
\hline Encontros/Data & Turnos/Duração & Temática & Ações/Fundamentação \\
\hline \multirow{3}{*}{$\begin{array}{l}\text { Primeiro } \\
11 / 09\end{array}$} & \multirow[b]{2}{*}{$\begin{array}{l}\text { Matutino } \\
4 \text { horas }\end{array}$} & Sensibilização dos colaboradores & $\begin{array}{l}\text { Apresentação da proposta e alinhamento dos } \\
\text { aspectos pertinentes à sua realização }\end{array}$ \\
\hline & & $\begin{array}{l}\text { Etnomatemática: } \\
\text { Prática }\end{array}$ & $\begin{array}{l}\text { Proposta de atividade realizada por Gerdes } \\
\text { (2013) e adaptada por Silva (2019), intitulada } \\
\text { Geometria e Cestaria dos Bora na Amazónia } \\
\text { Peruana }\end{array}$ \\
\hline & $\begin{array}{l}\text { Vespertino } \\
4 \text { horas }\end{array}$ & $\begin{array}{c}\text { Etnomatemática: Formalização } \\
\text { teórica }\end{array}$ & $\begin{array}{l}\text { Teorização da Etnomatemática por meio da } \\
\text { referência: } \quad \text { D’AMBROSIO, }^{\prime} \text { U. } \\
\text { Etnomatemática: Elo entre as tradições e a } \\
\text { modernidade. Belo Horizonte: Autêntica } \\
\text { Editora, 2001. }\end{array}$ \\
\hline \multirow[b]{2}{*}{$\begin{array}{l}\text { Segundo } \\
25 / 09\end{array}$} & $\begin{array}{l}\text { Matutino } \\
4 \text { horas }\end{array}$ & Modelagem Matemática: Prática & $\begin{array}{l}\text { Proposta de atividade extraída da experiência } \\
\text { realizada por Scheller, Bonotto e Biembengut } \\
(2016) \text {, intitulada Da Modelagem à Modelação } \\
\text { - Uma Prática Possível }\end{array}$ \\
\hline & $\begin{array}{l}\text { Vespertino } \\
4 \text { horas }\end{array}$ & $\begin{array}{l}\text { Modelagem Matemática: } \\
\text { Formalização teórica }\end{array}$ & $\begin{array}{l}\text { Teorização da Modelagem Matemática por } \\
\text { meio da referência: BIEMBENGUT, M. S. } \\
\text { Modelagem na educação matemática e na } \\
\text { ciência. São Paulo: Editora Livraria da Física, } \\
2016 \text {, v. } 1,367 \text { p. }\end{array}$ \\
\hline \multirow[t]{2}{*}{$\begin{array}{l}\text { Terceiro } \\
9 / 10\end{array}$} & $\begin{array}{l}\text { Matutino } \\
4 \text { horas }\end{array}$ & $\begin{array}{l}\text { Etnomodelagem: } \\
\text { Prática }\end{array}$ & $\begin{array}{l}\text { Uma atividade prática, realizada em grupo, } \\
\text { cujo contexto partiu dos envolvidos da } \\
\text { pesquisa, além de uma atividade prática } \\
\text { fundamentada em: CARDOSO, G. D.; } \\
\text { MADRUGA, Z. E. F. Etnomodelagem e o } \\
\text { extrativismo de caranguejos: Uma proposta } \\
\text { para a introdução do conceito de função linear. } \\
\text { Educação Matemática, Montes Claros, v. 1, } \\
\text { n. 3, } 2017 \text {. }\end{array}$ \\
\hline & $\begin{array}{l}\text { Vespertino } \\
4 \text { horas }\end{array}$ & $\begin{array}{l}\text { Etnomodelagem: } \\
\text { Formalização teórica }\end{array}$ & $\begin{array}{l}\text { Teorização da Etnomodelagem por meio da } \\
\text { referência: ROSA, M.; OREY, D. } \\
\text { Etnomodelagem: A arte de traduzir práticas } \\
\text { matemáticas locais. São Paulo: Editora } \\
\text { Livraria da Física, } 2017 .\end{array}$ \\
\hline
\end{tabular}

Fonte: Adaptado de Eça (2020, p. 137-138)

Participaram da formação 11 professores de um município do interior da Bahia. Esse quantitativo de professores correspondia a $100 \%$ do corpo docente que lecionava o componente curricular de Matemática nos anos finais do Ensino Fundamental. Desse grupo de participantes da formação havia: licenciado em Pedagogia, licenciado em Matemática, licenciado em Ciências; licenciado em Artes, licenciado em computação e estudante de Licenciatura em Matemática.

Dos 11 professores que ensinavam Matemática na época, somente 3 aceitaram voluntariamente continuar a pesquisa após o término do processo formativo, denotados, aqui, de Professor A (44 anos, gênero feminino, possui graduação em pedagogia e atua há 17 anos na docência), Professor B (43 anos, gênero masculino, possui graduação completa em pedagogia, licenciatura em matemática e atua há 17 anos na docência) e Professor C (25 anos, 
gênero masculino, está cursando licenciatura em matemática e atua há 1 ano na docência). Assim, esta pesquisa terá em seu escopo somente a análise dos dados provenientes desses 3 participantes. Para esses, foram realizadas entrevistas do tipo semiestruturada - uma vez que este modelo de entrevista permite uma flexibilidade, propiciando maior conforto ao participante para se expressar -, sendo esclarecido antecipadamente o protocolo do Comitê de Ética em Pesquisa $(\mathrm{CEP})^{6}$. O corpus de análise desta pesquisa foi formado pelas respostas dos professores à questão: $O$ que essa formação e os temas abordados, em especial a Etnomodelagem, acarretou para a sua prática docente?

Dessa forma, esse recorte possui uma dimensão qualitativa (BOGDAN; BIKLEN, 2010), na qual utilizou-se como metodologia de análise a Análise Textual Discursiva (ATD), a qual, segundo Morais e Galiazzi (2013), ancorada numa dimensão hermenêutica, proporciona um processo de compreensão do fenômeno investigado de modo dinâmico e flexível.

De acordo com Moraes e Galiazzi (2013), esse tipo de análise segue em três etapas: (i) desconstrução e unitarização (unidades de sentido); (ii) categorização (relações entre o que foi unitarizado); e (iii) construção dos metatextos a partir das interpretações dos investigadores. $\mathrm{O}$ início do desenvolvimento da ATD se deu por meio da unitarização ou desmontagem do texto oriundo das entrevistas. Essa etapa consistiu em separar as mesmas unidades de significado (que foram oriundas das respostas dos indivíduos investigados) em subconjuntos interligados com uma visão empírica do analista ou da teoria (MORAES; GALIAZZI, 2013).

Posteriormente, foi realizado um processo auto-organizado, denominado categorização. Este se deu por meio do movimento pendular, que oscilou em torno da desorganização, desconstrução e reconstrução dos significados/sentidos sobre o corpus de análise, construindo categorias iniciais, intermediárias e finais. E, finalmente, a elaboração do metatexto, que foi pautada na exposição descritiva das novas concepções através das categorizações. Evidenciouse que tal constituição se deu por meio das etapas de unitarizações, categorizações e, por fim, na elaboração do metatexto.

Após o desenvolvimento das etapas da ATD, cujo intuito foi estabelecer a busca pela compreensão do corpus que compõe os dados da pesquisa, emergiram quatro categorias que são o enfoque deste texto, a saber: a) processo formativo; b) docência; c) currículo; e d) abordagem dialógica.

\section{Resultados e discussão}

A análise enfocou apenas uma questão da entrevista, entretanto, fez emergir reflexões sobre a própria formação vivenciada, trazendo questionamentos sobre aspectos da docência, o currículo e sobre a abordagem dialógica da Etnomodelagem. Para discutir as três primeiras categorias, foi feito um diálogo com autores que abordam a dimensão colaborativa de formação e o currículo e docência.

\subsection{Processo formativo}

Esta categoria reúne elementos colaborativos, interativos e de união entre os aspectos teóricos e empíricos da Etnomodelagem, que foram utilizados durante todo o processo formativo. Por estas razões é que se justifica a emergência a partir da análise dos dados. Assim, são trazidas à luz nesta seção possíveis contribuições que foram identificadas durante todo o

\footnotetext{
${ }^{6}$ Aprovado sob o CAAE: 20334719.9.0000.5526.
} 
processo formativo, sobretudo referente à emancipação de fala do professor que se enxergou parte integrante das ações planejadas e desenvolvidas. Sob esses aspectos, Damiani (2008, p. 215) ressalta que haja "[...] as atividades realizadas em grupo, de forma conjunta, [pois] oferecem enormes vantagens, que não estão disponíveis em ambientes de aprendizagem individualizada". Narrativas dos participantes que embasam um elo com essas discussões podem ser observadas nas seguintes colocações: "E com certeza, não só pra mim, mas acredito que pra maioria, o contato entre os pares e a colaboração foi muito pertinente, né?", "[...] foi muito importante ter esse contato com outros profissionais e ouvir outros profissionais", e "[...] a gente sabe o quão importante é esse ambiente colaborativo que foi criado dentro da formação" (Professor C, 2019).

O escopo disso é proporcionar um trabalho pautado na superação de determinadas vaidades, ou individualismos, por meio da integração coletiva que o viés colaborativo proporciona. Isso pode ser verificado na seguinte explanação: “[...] a partir do momento que o professor se enxerga como parte integrante daquele curso, que a sua voz é ouvida" (Professor C, 2019). Isso está em consonância com Fiorentini e Crecci (2013, p. 19), pois os autores defendem que "[...] para investigar os processos de constituição das(s) identidade(s) dos professores em comunidades investigativas, é necessário dar-lhes voz e vez". O que sugere a acepção de ter sido uma formação com os professores, e não para os professores.

A tônica da perspectiva colaborativa durante a formação produziu, também, um sentimento de pertencimento e empoderamento dos professores durante o desenvolvimento das etapas, uma vez que a participação de todos foi conduzida de maneira planificada e horizontal, sobretudo interativa, por meio da dialogicidade (FREIRE, 1996) e da práxis docente (PIMENTA; LIMA, 2006). Naturezas que podem ser observadas a partir dos relatos: "Esse contato entre os professores em grupos, onde se deu voz aos professores, valorizou o debate"(Professor C, 2019) ou: "A gente sabe o quão importante é esse ambiente colaborativo que foi criado dentro da formação" (Professor C, 2019).

Percebe-se sob esse prisma a planificação de fala dos participantes, o que traz à luz a vertente dos princípios colaborativos, uma vez que, segundo Damiani (2008, p. 214), “[...] grupos colaborativos são aqueles em que todos os componentes compartilham as decisões tomadas e são responsáveis pela qualidade do que é produzido em conjunto, conforme suas possibilidades e interesses".

Além disso, Damiani (2008) acrescenta que a prática reflexiva das diferentes dimensões que compõem o cenário educativo entre os próprios pares de ofício se constitui como essencial na identificação de problemas inerentes ao trabalho que, inclusive, de maneira individual não seria possível. Esse ambiente de compartilhamento de informações que envolvem encaminhamentos de acertos e equívocos promove confrontação de ideias e pontos de vista, fato que gera discussões comprometidas com a prática pedagógica. Além disso, outras falas como: "[...] o professor se enxerga como parte integrante daquele curso, que a sua voz é ouvida" (Professor C, 2019) ou: “[...] como um sujeito ativo mesmo nesse processo, né?" ou, ainda: "[...] como foi bem dinâmica a formação, que muitas vezes você partia da prática" (Professor C, 2019), reforçam e ratificam que os professores se engajaram e se tornaram elemento integrante do processo.

A prática, sem a base teórica, recai no senso comum, e a teoria, sem a prática, não se sustenta, muito menos se refina. Corrobora-se, nesse sentido, com Pimenta e Lima (2006), ao afirmarem que não existe uma dicotomia entre teoria e prática, ou vice-versa, pois ambas são constituídas imbricadas em um ciclo mútuo e inseparável. Afinal, a teoria se estabelece imbricada da prática, que, inclusive, concebe e direciona novas facetas à teoria (PIMENTA, 
1995). Marcadores de falas dos participantes que convergem para isso estão nos seguintes depoimentos: "[...] No sentido de o professor buscar olhar para as suas práticas, né? Que é a questão da práxis, a gente precisa fazer a práxis. Refletir sobre as suas práticas” ou, ainda: “[...] sempre você partia da prática, e vinha pra teoria" (Professor C, 2019).

Diante disso, pode-se inferir que o processo formativo proporcionou aos participantes, conduzido por um viés praxiológico, profundas e constantes reflexões, o que pode ter contribuído para o seu desenvolvimento profissional, principalmente por meio da ressignificação de sua própria prática docente. Ao encontro dessa percepção, sublinham-se as seguintes afirmativas: "Porque hoje, antes de abordar o conteúdo, eu penso duas vezes" (Professor B, 2019) ou: "Então, a visão hoje [após o processo formativo] é totalmente diferente" (Professor B, 2019. Ainda: "Mas hoje eu tenho uma visão diferente" (Professor B, 2019).

Essas falas, associadas ao planejamento das ações do processo formativo, ganham um sentido mais nítido, posto que uma das intencionalidades que permeiam esse ambiente formativo interativo era construir e desconstruir coletivamente saberes e paradigmas engessados que pairam sobre a educação desde outrora, vinculada, especialmente, aos modos tradicionais das formações. De acordo com Fiorentini e Lorenzato (2009), essa perspectiva formacional valoriza o conhecimento sistematizado, dando ênfase aos saberes científicos (seja acadêmico ou escolar), deixando, desse modo, de dialogar com outros saberes que não pertencem a esse núcleo institucionalizado do saber, mas que estão inseridos na realidade dos estudantes.

Outros marcadores que merecem destaque estão expressos nas seguintes falas: "No sentido de contrapor aquelas formações, que volto a dizer, que vêm sendo disseminadas desde os anos sessenta e setenta" (Professor C, 2019); "O professor, quando submetido a uma formação continuada, ele se enxerga como um ser passivo" (Professor A, 2019); "Formações tradicionais remetem a uma única fala, a do formador" (Professor B, 2019); "Após o monólogo, o formador entrega uma ficha e a recebe no final" (Professor C, 2019), "Sendo a única voz, desconsiderando completamente o professor e o processo por sua vez, está ali tentando aprender, para depois reproduzir, né?" (Professor A, 2019); ou: "Ele chega e se coloca em uma posição de que o formador traz consigo determinado aporte teórico" (Professor B, 2019).

Esses aspectos que estão associados aos modus operandi que a formação se propôs a fazer, naturezas que se diferenciam de outras formações que aconteciam no município, materializadas pela concepção reprodutivista do saber, deslocadas dos anseios dos envolvidos, muito menos, dos aspectos socioculturais do território. Salienta-se, nesse sentido, segundo Fiorentini e Crecci (2013, p. 16), que “[...] no Brasil, o modelo majoritário de práticas indutoras ou catalisadoras de desenvolvimento profissional pode ser considerado ainda fortemente alinhado ao modelo da racionalidade técnica".

Essa visão de formação verticalizada, que se constitui do palestrante para o professor, traz à tona a concepção "externalista" (fora) para a "internalista" (dentro), o que, normalmente, não atende aos interesses dos envolvidos, pois são formações que privilegiam o cunho teórico e técnico dos objetos de conhecimento, mas que não correlacionam com as dimensões sociais, políticas, culturais e educacionais da comunidade local. Efeito que pode gerar a passividade do professor, uma centralização do saber no professor-formador, um monólogo do professorformador com ele próprio, um planejamento de teorias que estão desvinculadas com a realidade local, entre outros aspectos. Falas dos participantes que convergem a isso podem ser observadas nos seguintes trechos: "Se o professor, quando submetido a uma formação continuada, ele se enxerga com o passivo, naquele ambiente", "Essas formações bem tradicionais em que o 
formador impõe e fala durante todo o tempo" ou, ainda: "fica aquele monólogo e depois pega uma ficha, dá pro professor" (Professor C, 2019).

Em face do apresentado e discutido, inclina-se ao entendimento de que houve indícios de contribuições para/no desenvolvimento profissional dos professores participantes, posto que as ações desenvolvidas buscaram refletir profundamente as diversas variáveis que perfazem a prática docente do professor que ensina matemática por meio de uma perspectiva dialógica, que se propõe escutar e, a partir de então, definir a próxima ação. Essa trilha metodológica pode desencadear na construção da identidade profissional do professor que possui em seu escopo docente a emancipação dos saberes plurais que são construídos em diferentes espaços sociais. Nesse sentido, Fiorentini e Crecci (2013, p. 15) afirmam que existe, nesse ambiente formativo, a

[...] necessidade da participação plena dos professores, seja na elaboração de tarefas e práticas concernentes ao próprio desenvolvimento profissional, seja na realização de estudos e investigações que tenham como ponto de partida as demandas, problemas ou desafios, que os professores trazem de seus próprios contextos de trabalho na escola.

Corroborando com isso, Day (2001) afirma que as atividades produzidas pelos próprios envolvidos em uma formação promovem uma reflexão com significado, seja de maneira individual ou coletiva, o que, por outras vias, poderia não acontecer. Com efeito, esse movimento pode deflagrar uma aproximação dos pilares do professor reflexivo em sua prática, a saber: a reflexão sobre a ação; a reflexão na ação; e a reflexão sobre a reflexão na ação.

\subsection{Docência}

Esta categoria se sustenta pela referência que os professores participantes fazem de sua própria prática docente. Destacam-se os apontamentos que vão ao encontro do aporte teórico adotado nesta pesquisa, que discorrem sobre o individualismo entre os pares no ambiente de trabalho. Emergiu da análise desta pesquisa a preocupação dos participantes em relação à individualidade do professor que se concentra na sua própria prática, que rompe com as possibilidades de construção coletiva e/ou colaborativa durante o curso da prática docente. Essa percepção tornou-se mais nítida quando foi exposto que "[...] ninguém quer compartilhar nada com ninguém, é cada um isolado na sua prática e pronto" (Professor C, 2019). De acordo com Gama e Fiorentini (2009, p. 453),

[...] nos grupos colaborativos, essa cultura individualista tende a ser minimizada, pois os participantes são instigados a realizar novas experiências e a compartilhá-las com o grupo. Além disso, sentem-se valorizados quando participam expondo ideias, textos, projetos e materiais de apoio didático-pedagógico.

Isso, para Cavalcanti (2018, p. 7), representa que "O primado da individualidade tornouse o centro de interesse dos valores e do conhecimento". Essa tônica está acompanhada de uma crítica ao que ocorre nas escolas, isto é, revela que o professor, em seu local de trabalho, se isola em si mesmo, e não compartilha, portanto, saberes ou quaisquer reflexões inerentes a este ambiente. Interligado a esse ponto, a fala: "Que isso, por vezes, na escola, é muito compartimentado" (Professor C, 2019) traduz-se como um efeito dessa individualidade 

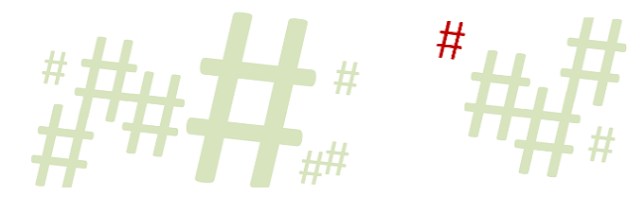

docente. Esse cenário provoca o compartimento de saberes e, consequentemente, a ruptura de um trabalho interdisciplinar. Segundo Morin (2000, p. 36):

[...] a esse problema universal confronta-se a educação do futuro, pois existe inadequação cada vez mais ampla, profunda e grave entre, de um lado, os saberes desunidos, divididos, compartimentados e, de outro, as realidades ou problemas cada vez mais multidisciplinares, transversais, multidimensionais, transnacionais, globais e planetários.

Em alinhamento a esse pensamento, Fiorentini e Crecci (2013, p. 16) acrescentam que há duas perspectivas que, por vezes, se confundem, e são difundidas pelas Secretarias de Educação (estadual ou municipal): “[...] a individualizada, que tenta suprir os déficits da formação inicial dos professores por meio de cursos e oficinas, e a colaborativa, que enfoca atividades realizadas predominantemente nas escolas, com ênfase no trabalho compartilhado". De acordo com Cavalcanti (2018), a constatação refere-se ao que René Descartes, em meados do século VII, chamou de paradigma mecanicista. Cavalcanti $(2018$, p. 17) discorre que a prática gera uma “[...] compartimentalização do conhecimento, em que o conteúdo é tratado em sua forma fragmentada, dividida e separada da complexidade da realidade".

Esse cenário educacional não permite que haja uma compreensão ampla e integradora do saber; ao contrário, valoriza o isolamento do saber e de maneira fragmentada. Em outra via, apresentando-se como contraponto a essa tendência, a concepção interdisciplinar visa à conexão entre os saberes de diversas áreas. A formação apresentou aspectos dessa concepção, evidenciados na verbalização do seguinte comentário: "Foi muito importante ter esse contato com outros profissionais e ouvir outros profissionais" (Professor A, 2019). Seu sentido associa a raiz que alimenta a concepção interdisciplinar, que parte do pressuposto colegiado entre os professores, superando, assim, esse individualismo docente e a fragmentação do saber.

Traz-se à tona uma ruptura com o sistema hierarquizado do conhecimento, posto de modo linear. Cavalcanti (2018, p. 28) afirma que a educação pautada em ações tende a "abrir o campo de visão das áreas do conhecimento, negando certezas dogmáticas e isolamentos teóricos em prol da abertura à pluralidade de relações e perspectivas por meio de um olhar mais crítico e reflexivo sobre o mundo e sobre a própria ideia de conhecimento". Salienta-se que, para esse feito, faz-se necessária uma prática docente sob a construção coletiva e participativa, assim, a individualidade e as causas que ela propõe se dissipam.

\subsection{Currículo}

Percebeu-se que, após a ação formativa, os professores refletiram sobre a utilização do livro didático como a única fonte de consulta ou instrumento de trabalho, confundindo-o, inclusive, com o próprio currículo. Além disso, apoiado nas falas: "Eu digo assim, antes estava no livro ali bitolado" (Professor A, 2019); "Porque a gente tem o livro como ferramenta principal" (Professor B, 2019); ou: "mas eu ficava preso ali no livro" (Professor B, 2019), foi possível ampliar a discussão sobre o impacto do livro sobre a prática docente, uma vez que o professor, condicionado no livro didático como instrumento norteador de sua prática, limita em um subconjunto a construção do saber. Não raramente, ora confunde-se a concepção de currículo como sendo o próprio livro didático ora concebe-se o currículo como um conjunto seleto e inflexível de conhecimento que predispõe o que se deve ensinar e/ou reproduzir. Nesse sentido, Macedo (2007, p. 25) salienta que o currículo é vivido "[...] cotidianamente, enquanto 
concepção e prática, a reprodução das ideologias, bem como permite, de alguma forma, a construção de resistências, bifurcações e vazamentos".

Sob esse prisma, o professor simboliza a ferramenta operacional desse sistema. No entanto, para além dessa perspectiva, Macedo (2007) destaca que currículo é parte integrante do âmbito escolar e, por assim entender, todo agente do meio faz parte do currículo e, por vezes, se confunde com tal. Em outras palavras, o autor destaca ser necessário haver mais interação entre os membros da comunidade escolar, em especial o professor, com os saberes e fazeres que emanam desse cenário para assim alinhar-se com as diretrizes pedagógicas nacionais que visam a uma educação que promova a participação crítica e reflexiva do cidadão perante a sociedade que o cerca.

Aliado a isso, o professor retorna a uma prática deslocada da realidade na qual está inserido, não podendo, dessa forma, dialogar com os saberes que são produzidos pelos próprios alunos. As reflexões da formação não demonizam o livro, pelo contrário, ressaltam a sua importância. Porém exprimem, também, a influência que este instrumento exerce sobre o professor, pondo-o num lugar confortável e sob elementos prontos e acabados. Essa centralização no livro ocasiona uma estrutura inflexível na prática docente, valorizando mais os conteúdos do que as habilidades de sua construção. Aliás, conduzir o ato de ensinar unicamente por meio dessa via é não somente limitar-se quanto ao todo, mas desvincular-se do meio que cerca o docente. O que ressoa a natureza sistemática e padronizada do saber. Ao contrário disso, Moreira e Silva (2002, p. 7-8) destacam que

O currículo não é um elemento inocente e neutro desinteressado do conhecimento social. O currículo está implicado em relações de poder, o currículo transmite visões sociais e particulares e interessadas, o currículo produz identidades individuais e sociais particulares. O currículo não é um elemento transcendente e atemporal - ele tem uma história, vinculada às formas específicas e contingentes de organização da sociedade e da educação.

Percebeu-se que a formação trouxe, além da reflexão acerca do livro didático, a busca por outras fontes. $\mathrm{O}$ distanciamento da via exclusiva desse instrumento concretiza-se por meio dos excertos: "Eu digo assim, que aquela formação me ajudou a desprender do livro, a desprender" (Professor B, 2019) e "Hoje, eu preciso do livro, mas que ele não é o tudo" (Professor B, 2019), que sinalizam a busca de outras possibilidades para fundamentar a prática pedagógica realizada na escola. Isso fica perceptível quando se expõe a fala: "Porque não adianta a gente querer pregar, não adianta ter currículo" (Professor C, 2019), visto que nela está contido um sentido de inferência a um currículo que não dialoga com a prática docente ou com os fazeres-saberes que seus alunos praticam-produzem nas suas respectivas localidades.

Essa mudança de postura pedagógica perpassa a visão da construção de conhecimento de forma internalista. Ao contrário, Vergani (2007) aponta a integração dos saberes apreendidos na escola com a realidade que a cerca. A autora ainda acentua a necessidade de um novo ambiente de aprendizagem, que interligue as "[...] dimensões psicológicas e socioculturais do ato educativo" à integralidade entre escola/sociedade, que, por vezes, se mantêm desconectados (VERGANI, 2007, p. 26).

Para tanto, chama-se a atenção para um efeito que traduz em si uma contribuição da formação para seu desenvolvimento profissional, evidenciada na seguinte fala: "De um currículo que fale da importância do aluno como sujeito ativo, da importância da construção" (Professor C, 2019). Isso se mostra no sentido oposto ao que se prega no individualismo 
profissional, que também foi objeto de análise. Esse distanciamento tem como base inicial a dissipação da ideologia individualista impregnada no fazer pedagógico dos professores participantes, fato que, por si só, já se torna de grande importância como produto das açõesreflexão oriundas da formação.

\subsection{Abordagem dialógica}

Esta categoria envolve, dentre outras facetas, a presença marcante da busca dos professores participantes de se aproximarem da realidade do aluno. Nessa linha de raciocínio, ficam expostos os fazeres e saberes que os estudantes praticam em suas localidades. No entanto, existe influência significativa do livro didático sobre a prática do professor. Posto que a concentração da prática no livro limita o fazer pedagógico, portanto, deve-se considerar outras perspectivas.

Assim, existe um interesse em efetivar esse elo entre os saberes estudados na escola e os saberes construídos fora dela. Essa intencionalidade é observada no comentário "[...] tenho aquela preocupação de gerar uma outra situação a partir daquela ali, que seja aplicada dentro do seu [estudante] contexto" (Professor B, 2019). Embora os professores participantes tenham mencionado um caminho que é "[...] trazer situações oriundas do cotidiano e compreender a matemática presente na vida do aluno" (Professor C, 2019), isso ainda não é praticado pelos mesmos.

É notório que essa união entre os saberes locais e globais, que segundo Rosa e Orey (2017) podem ser chamados de glocais, devem ser articulados no processo de ensino e de aprendizagem. Percepção essa que é reiterada pelos próprios professores, ao mencionarem "Os conhecimentos lá da marisqueira, aquele conhecimento daquela pessoa lá que vai incubar uma terra" (Professor C, 2019); "E trazer situações oriundas do cotidiano e compreender a matemática presente na vida do aluno" (Professor C, 2019); ou "[...] uma comunidade de pescadores que já tem seus costumes, por exemplo, tem aquelas formas de medir para fazer a rede e tudo mais" (Professor A, 2019). Isso ganha sentidos que se intensificaram quando dialogamos sobre a perspectiva da Etnomodelagem, abordada ao longo da formação.

Para Rosa e Orey (2010), a escola deve considerar os saberes globais e locais numa abordagem dialógica. Assim as manifestações matemáticas, em especial nas situações cotidianas, se tornam visíveis. A compressão sob essa ótica acarreta numa valorização cultural de grupos marginalizados socialmente, nos quais os estudantes estão inseridos. Concepção que converge com a análise de Orey e Rosa (2018, p. 186) ao afirmarem que:

[...] na abordagem dialógica pode-se evidenciar a interdependência e a complementaridade entre as abordagens êmica e ética. Por conseguinte, essa abordagem possibilita que os investigadores e educadores questionem os próprios vieses e preconceitos ao se tornarem familiares com as diferenças culturais que são relevantes para os membros de cada grupo cultural.

Assim, para os autores, esses saberes precisam ser legitimados não somente entre seus próprios membros, sobretudo, é necessário que no âmbito escolar essa tônica prevaleça, diminuindo, assim, a opressão e as injustiças sociais que os mesmos sofrem. Dessa forma, os instrumentos de natureza matemática presentes em amplos e vastos espaços sociais, principalmente aqueles que se aproximam da realidade dos estudantes, devem ser incorporados 
ao currículo, a fim de valorizar as práticas matematizantes realizadas, além de questionar o modelo histórico padronizado do saber.

Realizar ações voltadas para esses objetivos é materializar as intenções de "Fazer com que eles entendam que a matemática é importante" (Professor C, 2019), pois a mesma "faz parte da vida deles" (Professor A, 2019). Para tanto, precisa-se de uma abordagem metodológica que construa e promova, na relação teórico-prático, uma identidade cultural no estudante, sobretudo que o insira no processo de ensino e de aprendizagem de forma dinâmica e participativa. Nesse segmento, a inobservância da realidade do estudante se torna incompatível com seus preceitos.

É importante, nesse sentido, que a escola se torne um ambiente de enfrentamento a questões relacionadas a situações de opressões ou de injustiças sociais que envolvem grupos sociais marginalizados ou minoritários. Assim, a abordagem dialógica, e a própria Etnomodelagem, se candidata como elo dessa corrente ideológica, principalmente por produzir possibilidades que se voltem à conscientização de que existem saberes matemáticos concebidos e praticados de modos diferentes, o que, de nenhuma maneira, deve ser entendido sob um aspecto hierárquico entre si.

Aliás, essa natureza conceitual, além de valorizar amplos e diversos saberes, revela à sociedade acadêmica e civil que existem várias maneiras de praticar a Matemática, pensamento que, em outrora, era refutado pela ideia colonial que girava em torno de um só berço do saber: a Europa. Essa reformulação de eixo, colocando os saberes extraescolares com elos em práticas socioculturais, tendo como enfoque a realidade dos estudantes, devem ser cada vez mais incorporados nas aulas a fim de problematizar o modelo histórico padronizado do saber. Para tanto, a metodologia deve ajudar a construir e promover, na relação teórico-prático, uma identidade cultural no estudante, sobretudo, que o insira no processo de ensino e aprendizagem de forma dinâmica e participativa, tendo como elemento catalisador os saberes matemáticos praticados em seu território.

\section{Considerações finais}

Esta pesquisa investigou os significados da Etnomodelagem que emergiram durante uma ação formativa com professores de Matemática de um município do interior da Bahia, questionando quais os significados da Etnomodelagem que emergiram durante uma ação formativa com professores de Matemática de um município do interior da Bahia?

A análise realizada permitiu capturar os significados atribuídos pelos professores a essa temática. Considera-se que esses professores compreenderam a Etnomodelagem como uma abordagem metodológica e dialógica que visa, principalmente, à valorização dos saberes matemáticos dos estudantes e da Matemática praticada pelos diversos grupos culturais e sociais aos quais pertencem, por exemplo, das comunidades de marisqueiras e pescadores. Além disso, os professores trouxeram à tona outras reflexões, direcionadas para outras dimensões relacionadas ao próprio processo formativo: docência e currículo, condições indispensáveis para o desenvolvimento/efetivação dessa abordagem na escola.

O processo formativo vivenciado com os professores buscou tensionar o modelo de formação baseado na racionalidade técnica, em que as ações são pensadas de modo vertical, e não horizontal, como proposto nesta pesquisa. Isto é, as reflexões e discussões profícuas tinham como base as próprias práticas dos envolvidos, o que gerou construções e desconstruções de naturezas distintas, dentre as quais merece destaque a percepção de quão se produz de Matemática no seio social dos estudantes que, por vezes, são negligenciados pelo currículo escolar. 
Uma das consequências a esse intento foi o desenvolvimento do protagonismo docente durante as ações, deixando os participantes cada vez mais pertencentes de todas as etapas da formação, ou seja, construiu-se um vetor integrador e ativo essencial para o transcorrer da pesquisa. Esse protagonismo trouxe à tona - por meio da reflexão docente - um ensaio para mudanças na prática pedagógica. Ao menos, foi constatada a predisposição dos participantes a essa vertente, que de maneira isolada pode transparecer uma ação tímida, mas representa um passo importante.

Foi notabilizado pelos participantes a mudança de fala/pensamento/atitudes sobre o ensino de Matemática, em especial reconhecendo a importância de se buscar bases teóricas para fundamentar as suas práticas docentes, a fim de utilizá-las em prol da construção de cidadãos conscientes e politizados em seu meio social, utilizando, para tanto, o próprio território que, sobretudo, se candidata como um laboratório - carregado de simbologias e significados , propício e de grande potencialidade para exploração de saberes diversificados, entre eles, matemáticos. Com efeito, desconstrói-se a concepção cuja perspectiva valorizava como única via a matemática colonial/eurocêntrica frente aos conhecimentos populares e pluralizados presentes nas práticas de diferentes grupos sociais, fissurando, assim, a concepção de supremacia de culturas, povos e saberes. Mudanças essas que inevitavelmente culminam na problematização do currículo vigente.

As discussões se distanciaram das perspectivas que se coadunam com as práticas docentes reprodutivistas e/ou hegemônicas e se aproximaram daquelas que tinham como base epistemológica outras conotações acerca da reflexão sobre os fenômenos que estão à sua volta, tendo como enfoque os aspectos socioculturais. Assim, revela-se como um ato político a tentativa de trazer à luz os saberes locais para pauta do currículo escolar, o que representa uma forma de valorizar as singularidades dos sujeitos/estudantes e diminuir as injustiças e/ou exclusões sociais.

Por fim, outro tocante de natureza significativa da formação foi o entendimento que os construtos teóricos debatidos permeiam, entre outras coisas, numa valorização dos saberes do discente, advindos de seu território. Assim, a Matemática serve de instrumento para o resgate ou construção da identidade cultural desses sujeitos, o que gera como consequência o sentimento de pertencimento/empoderamento, logo de emancipação social e política desse público diante dos fenômenos pejorativos que a sociedade ainda persiste em perpetuar nas veias que alimentam o sistema opressor.

A propósito, a educação é constituída na dimensão social e, sendo assim, envolve-se numa relação teórico-prático que tem cunho e compromisso político que precisa ser exercitado, principalmente nos meandros do ambiente educativo, proposição que se levantou, também, neste trabalho. Isso implica, entre outros aspectos, inserir e exercer uma prática no contexto educativo, voltada para o reconhecimento e para a valorização dos saberes diversificados que são praticados por diferentes membros de grupos sociais, especialmente aqueles marginalizados, que carregam em si estigmas sociais históricos. 


\section{Referências}

BAHIA. Secretaria da Educação. Superintendência de Políticas para Educação Básica. União Nacional dos Dirigentes Municipais da Bahia. Documento curricular referencial da Bahia para educação infantil e ensino fundamental. 475p., 2019. Disponível em:

http://escolas.educacao.ba.gov.br/sites/default/files/private/midiateca/documentos/2020/docu mentocurricularbahia.pdf. Acesso em: 8 set. 2020.

BRASIL. Base nacional comum curricular. 3. versão. Brasília: MEC, 2017. Disponível em: http://basenacionalcomum.mec.gov.br/images/BNCC_EI_EF_110518_versaofinal_site.pdf. Acesso em: 8 set. 2020.

BOGDAN, R.; BIKLEN, S. Investigação qualitativa em educação. Porto: Porto Editora, 2010.

CAVALCANTI, M. A. de P. Redes de saberes: Pensamento interdisciplinar. Revista Periferia, Rio de Janeiro, v. 10, n.1, p. 16-30, 2018. Disponível em: https://www.epublicacoes.uerj.br/index.php/periferia/article/view/12478/24533. Acesso em: 8 set. 2020.

DAMIANI, M. F. Entendendo o trabalho colaborativo em educação e revelando seus benefícios. Revista Educar, Curitiba, n. 31, p. 213-230, 2008. Editora UFPR. Disponível em: https://www.scielo.br/pdf/er/n31/n31a13.pdf. Acesso em: 8 set. 2020.

DAY, C. Desenvolvimento profissional de professores: Os desafios da aprendizagem permanente. Porto: Porto Editora, 2001.

EÇA, J. L. M. Formação continuada à luz da etnomodelagem: Implicações para o desenvolvimento profissional do professor que ensina matemática. 2020. Dissertação (Mestrado em Educação em Ciências e Matemática) - Universidade Estadual de Santa Cruz, Ilhéus, 2020. Disponível em: http://www.biblioteca.uesc.br/biblioteca/bdtd/201820004D.pdf. Acesso em: 14 out. 2021.

EÇA, J. L. M. DE; MADRUGA, Z. E. DE F. A Etnomodelagem na formação de professores: Uma análise a partir de produções recentes. Revemop, v. 3, p. e202105, 24 mar. 2021 a. Disponível em: https://periodicos.ufop.br/revemop/article/view/4778. Acesso em: 28 ago. 2021.

EÇA, J. L. M.; PEIXOTO, J. L. B.; MADRUGA, Z. E. F. Formação continuada à luz da Etnomodelagem: Construção de uma proposta de ensino com professores que ensinam matemática no ensino fundamental. Reamec - Rede Amazônica de Educação em Ciências e Matemática, [S. l.], v. 9, n. 1, p. e21005, 2021b. Disponível em:

https://periodicoscientificos.ufmt.br/ojs/index.php/reamec/article/view/11384. Acesso em: 29 ago. 2021.

FIORENTINI, D.; CRECCI, V. Desenvolvimento profissional docente: Um termo guardachuva ou um novo sentido à formação? Revista Formação Docente, Belo Horizonte, v. 5, n. 8, p. 11-23, jan./jun. 2013. Disponível em:

https://revformacaodocente.com.br/index.php/rbpfp/article/view/74. Acesso em: 8 set. 2020. 
FIORENTINI, D.; LORENZATO, S. Investigação em educação matemática: Percursos teóricos e metodológicos. 3. ed. Autores Associados, 2009.

FREIRE, P. Pedagogia da autonomia: Saberes necessários à prática educativa. São Paulo: Paz e Terra, 1996.

GONÇALVES, P. A etnomodelagem no contexto da carcinicultura cearense: Possibilidades para a sala de aula. Revista de Ensino de Ciências e Matemática, v. 12, n. 2, p. 1-20, $1^{\text {o }}$ mar. 2021. Disponível em:

https://revistapos.cruzeirodosul.edu.br/index.php/rencima/article/view/2941. Acesso em: 14 ago. 2021.

MACEDO, R. S. Currículo: Campo, conceito e pesquisa. Petrópolis: Vozes, 2007, p. 140.

MORAES, R.; GALIAZZI, M. C. O jogo da compreensão na análise textual discursiva em pesquisas na educação em ciências: Revisitando quebra-cabeças e mosaicos. Ciência \& Educação, Bauru, v. 24, n. 3, p. 799-814, 2018. Disponível em: https://www.scielo.br/pdf/ciedu/v24n3/1516-7313-ciedu-24-03-0799.pdf. Acesso em: 8 set. 2020.

MOREIRA, A. F.; SILVA, T. T. Currículo, cultura e sociedade. São Paulo: Cortez, 2002.

MORIN, E. Os princípios do conhecimento pertinente. In: MORIN, E. Os sete saberes necessários à educação do futuro. São Paulo: Cortez, 2000.

OREY, D. C.; ROSA, M. Explorando uma abordagem dialógica da etnomodelagem: Traduzindo o conhecimento matemático local e global a partir de uma perspectiva sociocultural. Jornal Latino-americano de Etnomatemática, [S. l.], v. 11, n. 1, p. 179-210, 2018. Disponível em:

https://www.revista.etnomatematica.org/index.php/RevLatEm/article/view/485. Acesso em: 8 set. 2020.

PIMENTA, S. G. O estágio na formação de professores: Unidade entre teoria e prática. Revista Caderno de Pesquisa, São Paulo, n. 94, p. 58-73, 1995. Disponível em: http://publicacoes.fcc.org.br/ojs/index.php/cp/article/view/839. Acesso em: 8 set. 2020.

PIMENTA, S. G.; LIMA, M. S. L. Revista estágio e docência: Diferentes concepções. Poíesis, RJ, v. 3, n. 3, p. 5-24, 2006. Disponível em: https://www.revistas.ufg.br/poiesis/article/view/10542. Acesso em: 8 set. 2020.

RODRIGUES, J.; ROSA, M.; OREY, D. C. O (re)descobrimento do conhecimento matemático fora da escola a partir de uma trilha de matemática: Um estudo fundamentado na etnomodelagem. Revista Latinoamericana de Etnomatemática: Perspectivas socioculturales de la educación matemática, [S. l.], v. 14, n. 2, p. 54-75, 2021. DOI: 10.22267/relatem.21142.83. Disponível em: https://www.revista.etnomatematica.org/index.php/RevLatEm/article/view/571. Acesso em: 29 ago. 2021. 
Revista de Educação, Ciência e Tecnologia

ROSA, M.; OREY, D. C. Etnomodelagem: A abordagem dialógica de saberes e técnicas êmicas e éticas. Contexto \& Educação, Ijuí, v. 29, n. 94, p. 132-152, set./dez. 2014. Disponível em:

https://www.revistas.unijui.edu.br/index.php/contextoeducacao/article/view/3110. Acesso em: 3 dez. 2020.

ROSA, M.; OREY, D. C. Etnomodelagem: A arte de traduzir práticas matemáticas locais. São Paulo: Editora Livraria da Física, 2017.

ROSA, M.; OREY, D. C. Etnomodelagem como um movimento de globalização nos contextos da etnomatemática e da modelagem. Com a Palavra, o Professor, v. 5, n. 11, p. 258-283, 2020. Disponível em: http://revista.geem.mat.br/index.php/CPP/article/view/565. Acesso em: 8 set. 2020.

SOUSA, R. S.; GALIAZZI, M. do C. A categoria na análise textual discursiva: Sobre método e sistema em direção à abertura interpretativa. Revista Pesquisa Qualitativa, São Paulo, v. 5, n. 9, p. 514-538, 2017. Disponível em:

https://editora.sepq.org.br/index.php/rpq/article/view/130. Acesso em: 8 set. 2020.

VERGANI, T. Educação etnomatemática: O que é? Natal: Flecha do Tempo, 2007. Coleção Metamorfose. Número especial.

Recebido em agosto de 2021.

Aprovado em outubro de 2021. 